Canadian

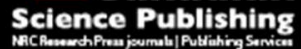

Canadian Journal of Physiology and Pharmacology Revue canadienne de physiologie et pharmacologie

\title{
Exogenous Hydrogen Sulfide Attenuates Cerebral Ischemia/Reperfusion Injury by Inhibiting Autophagy in Mice
}

\begin{tabular}{|r|l|}
\hline Journal: & Canadian Journal of Physiology and Pharmacology \\
\hline Manuscript ID & cjpp-2016-0100.R2 \\
\hline Manuscript Type: & Article \\
\hline Date Submitted by the Author: & $16-$ May-2016 \\
\hline Complete List of Authors: & $\begin{array}{l}\text { Shui, Mengyang; Peking University Health Science Centre, Department of } \\
\text { Molecular and Cellular Pharmacology } \\
\text { Liu, Xiaoyan; Peking University Health Science Centre, Department of } \\
\text { Molecular and Cellular Pharmacology } \\
\text { Zhu, Yuanjun; Peking University Health Science Centre, Department of } \\
\text { Molecular and Cellular Pharmacology } \\
\text { Wang, Yinye; Peking University Health Science Centre, Department of } \\
\text { Molecular and Cellular Pharmacology }\end{array}$ \\
\hline Keyword: & \begin{tabular}{l} 
Exogenous hydrogen sulfide;, MCAO;, mice; , autophagy;, LC3-II \\
\hline
\end{tabular} \\
\hline
\end{tabular}




\section{Exogenous Hydrogen Sulfide Attenuates Cerebral Ischemia/Reperfusion Injury by Inhibiting Autophagy in Mice}

Mengyang Shui, Xiaoyan Liu, Yuanjun Zhu*, Yinye Wang*

Department of Molecular and Cellular Pharmacology, School of Pharmaceutical Sciences, Peking University Health Science Center, Beijing 100191, China

* Author for correspondence

Yinye Wang

Tel: $86-10-82802652$

E-mail address: wangyinye@bjmu.edu.cn

Yuanjun Zhu

Tel: $86-10-82802652$

E-mail address: zhuyuanjun@bjmu.edu.cn 


\section{Abstract}

Hydrogen Sulfide, the third gas transmitter, has been proven to be neuroprotective in cerebral ischemia injury, but whether its effect is mediated by regulating autophagy is not yet clear. The present study was undertaken to explore the underlying mechanisms of exogenous $\mathrm{H}_{2} \mathrm{~S}$ on autophagy regulation in cerebral ischemia. The effects and its connection with autophagy of $\mathrm{NaHS}, \mathrm{a}_{2} \mathrm{~S}$ donor, were observed through neurological deficits and cerebral infarct volume in middle cerebral artery occlusion (MCAO) mice; autophagy related proteins and autophagy complex levels in ischemia hemisphere were detected with western blot assay. Compared to model group, NaHS significantly decreased infarct volume and improved neurological deficits; Rapamycin, an autophagy activator, abolished the effect of NaHS; NaHS decreased the expression of LC3-II and up-regulated p62 expression in ischemia cortex 24 hours after ischemia. However, NaHS did not significantly influence Beclin-1 expression. $\mathrm{H}_{2} \mathrm{~S}$ has neuroprotective effect on ischemia injury in MCAO mice, this effect is associated with its influence in down-regulating autophagosomes accumulation.

\section{Keywords}

Exogenous hydrogen sulfide; MCAO; mice; autophagy; LC3-II;

\section{INTRODUCTION}

Hydrogen sulfide $\left(\mathrm{H}_{2} \mathrm{~S}\right)$, formerly known as a toxic gas with odorous smell, has been testified as an endogenous signaling transmitter that regulates cellular function (Szabó 2007) and vasculartone (Zhao et al. 2001). The previous research has suggested that $\mathrm{H}_{2} \mathrm{~S}$ provides a protective effect for cerebral injury in rodent models and cellular models (Zhang and Bian 2014). Among these data, the effect of $\mathrm{H}_{2} \mathrm{~S}$ was partially due to inducing angiogenesis around the ischemia core (Jang et al. 2014) and promoting synaptic remodeling (Pradip et al. 2015). Moreover, its effect has been demonstrated in parallel with reduced oxidative stress, inflammation and apoptosis (Yin et al. 2013). 
Recently, the protective effect of $\mathrm{H}_{2} \mathrm{~S}$ has been allegedly associated with autophagy in myocardia (Jang and Xiao 2015), in spinal cord ischemia/reperfusion (I/R) (Li and Jiang 2015) and in traumatic brain injury (Zhang and Shan 2014). However, the exact connection of autophagy and $\mathrm{H}_{2} \mathrm{~S}$ in cerebral ischemia is not yet clear.

Autophagy is a highly conserved process, by which dysfunctional organelles and selected proteins are degraded in a sequestered double-membrane vesicle known as autophagosomes (Wong et al. 2013). Under ischemia insults, energy depletion and metabolic disorder contributes to the activation of energy sensing kinases like MTOR and AMPK, resulting to the activation of autophagy (Ai and Yue 2014). It requires several molecular complexes in the process of autophagosome formation, including the ULK1 kinase complex, the beclin-1-VPS34-AMBRA1 complex, Atg12-Atg5-Atg16L complex, effector proteins like WIPI-1 and-2, and binding proteins like LC3 and p62 (Nazio et al. 2013) . Among these, Beclin-1-VPS34-AMBRA1 complex, known as Beclin-1 complex, is usually considered as a vital participator in the initiation of starvation-induced autophagy. In this study, we aimed to investigate the elementary regulation of $\mathrm{H}_{2} \mathrm{~S}$ on autophagy activity in cerebral ischemia and the influence of $\mathrm{H}_{2} \mathrm{~S}$ on Beclin-1 complex.

\section{MATERIALS AND METHODS}

\section{Chemicals and antibodies}

$\mathrm{H}_{2} \mathrm{~S}$ donor, NaHS (Sodium hydrosulfide, 161527) was purchased from Sigma-Aldrich. Anti- $\beta$-actin (sc-47778, 1:1,000), Beclin-1 (sc-11427, 1:1,000) antibodies were purchased from Santa Cruz. Anti-LC3B/MAP1LC3B (NB600-1384, 1:1,000) antibody was purchased from Novus Biologicals. Anti-p62 (PM-045, 1:1,000) antibody and positive control for anti-LC3 antibody (PM036-PN) were purchased from MBL. Peroxidase-conjugated affinipure goat anti-rabbit IgG $(\mathrm{H}+\mathrm{L})(\mathrm{ZB}-2301,1: 2500)$ was purchased from ZSGB-BIO. Goat-anti-mouse IgG (IS001, 1:10,000) was purchased from M\&C Gene Technology. 3-MA (369172) and rapamycin (948477) were purchased 
from J\&K.

\section{Animals}

Male KM mice (22g-25g), were purchased from Laboratory Animal Center, Peking University Health Science Center. The experimental procedures and animals care administration were performed in accordance with the guidelines of Care and Use of Laboratory Animals by Beijing Committee on Animal Care and Use. The experiments were approved by the Committee on the Ethics of Animal Experiments of the Peking University Health Science Center.

\section{MCAO model in mice}

The procedures of MCAO model were adopted as previously described (Hara et al. 1996). Briefly, mice were anesthetized with chloral hydrate $(500 \mathrm{mg} / \mathrm{kg}$, ip). The body temperature was sustained at $37{ }^{\circ} \mathrm{C}$ with a heating surgery table. The right common carotid artery was exposed by a midline incision. Afterwards, right common carotid artery, internal carotid artery and external carotid artery were dissociated. A round tip 6-0 monofilament nylon suture was introduced into the internal carotid artery through an incision in the external carotid artery, and gently advanced 9-10mm until the rounded tip reached the origin of the MCA. An abrupt drop in cortical perfusion $(<25 \%$ of the baseline) indicates successfully occlusion, which was monitored by the laser Doppler flowmetry. 90 minutes later, the monofilament was gently removed, and then the external carotid arteries was permanently ligated.

\section{Intracerebral ventricular (icv) injection}

The treatment protocol was selected according to previous study (Finan et al. 2016). Mice were anesthetized with $5 \%$ chloral hydrate $(500 \mathrm{mg} / \mathrm{kg}$, ip) and placed in a small animal stereotaxic instrument (ZS-B, ZSLABL). The skull was exposed by an incision along with the sagittal suture and the bregma was revealed. Intracerebroventricular injection in the right lateral ventricle was performed according to the a location of -0.3 $\mathrm{mm}$ anteroposterior, $1.0 \mathrm{~mm}$ lateral, $-2.5 \mathrm{~mm}$ dorsoventral relative to bregma. A flat-ended syringe (TP-0003HPLCZ, GAOGE) was used to infuse the solution into the 
ventricle at a speed of $0.25 \mu 1$ per minute.

\section{Experimental groups and treatments}

Experiment 1: This experiment was performed for the observation of dose-effect relationship of $\mathrm{H}_{2} \mathrm{~S}$ protective action on cerebral ischemia. Mice were randomly divided in to sham group, model group (normal saline (NS-treatment)), and NaHS-treatment group in difference doses $(1 \mathrm{mg} / \mathrm{kg}, 2 \mathrm{mg} / \mathrm{kg}, 4 \mathrm{mg} / \mathrm{kg}, 8 \mathrm{mg} / \mathrm{kg}, 16 \mathrm{mg} / \mathrm{kg})$, NS or NaHS were intraperitoneal injected at onset of ischemia.

Experiment 2: Mice were randomly divided in to sham group, model group (normal saline), NaHS (2 mg/kg) group, NaHS (2 mg/kg) + RAP (35 pmol) group, NaHS (2 $\mathrm{mg} / \mathrm{kg})+$ RAP (70 pmol) group and 3-MA (400 nmol) group. Intracerebroventricular injection of rapamycin (35 pmol or $70 \mathrm{pmol})$ was administered ten minutes before ischemia. Rapamycin was dissolved in ethanol $(5 \mathrm{mg} / \mathrm{ml})$ and diluted with normal saline (the final ethanol concentration $<2 \%$ ). The 3-MA $(400 \mathrm{nmol})$ or normal saline was administered ten minutes before ischemia using icv injection. 3-MA was directly dissolved in normal saline by heating in $60^{\circ} \mathrm{C}$ water bath and cooled to room temperature immediately before icv injection (Gao, et al. 2012). NaHS was administered as previously described. This experiment was performed for the observation of the association of $\mathrm{H}_{2} \mathrm{~S}$ and autophagy in cerebral ischemia.

Experiment 3: Mice were randomly divided into sham group, model group and NaHS group. NaHS was administered as previously described. This experiment was conducted for western blotting analysis of autophagy associated proteins.

\section{Determination of neurological deficit and infarct volume}

Twenty-four hours after ischemia, the neurological deficit of mice in experiment 1 was evaluated with a blinded-manner using a well-established protocol (Serge et al. 2010). Mice of experiment 1 and 2 were anesthetized with chloral hydrate $(500 \mathrm{mg} / \mathrm{kg}$, ip) and transcardially perfused with cold normal saline. The brains were dissected rapidly and cut into five coronal slices, and stained with $2 \%$ of TTC for 30 minutes. Then slices were fixed in $4 \%$ PFA overnight and photographed the slices with a digital camera 
(Power-Shot G12, Cannon). The white regions were defined as infarct regions. The infarct volume was calculated with Image $J$ software (NIH Image), by measuring the white regions of each slice across the thickness of every slice. The corrected infarct volume was calculated with the formula as previous described (Jackman et al. 2011).

\section{Western blot}

Mice were anesthetized $24 \mathrm{~h}$ after ischemia and perfused with precooled PBS. Then cortex and striatum were respectively isolated form right hemispheres on ice and proteins were extracted from tissue samples in cold RIPA buffer supplement with $1 \%$ DTT and 1\% protease inhibitor cocktail (Sigma, P8340-1ML) (Zhang et al. 2013). Samples were separated by SDS-PAGE, and blots were incubated with rabbit anti-LC3 antibody, anti-Beclin1 antibody or anti-p62 antibody overnight at $4{ }^{\circ} \mathrm{C}$, respectively. Subsequently, blots were incubated with relevant secondary antibody at room temperature for 90 minutes. Ultimately, immunoreactivity was detected by ECL kit and quantified using the Imagelab software.

\section{Statistical analysis}

All data were represented as mean \pm SEM. Statistical significance among groups was measured by One-way ANOVA, followed by Tukey's test. $P<0.05$ was considered as statistically significant.

\section{RESULTS}

\section{Neuroprotective effects of $\mathrm{H}_{2} \mathrm{~S}$ in mice}

A remarkable brain infraction $(45.6 \% \pm 2.6 \%)$ and damage in motor function $(7.3 \pm 0.6)$ were resulted in $\mathrm{MCAO}$ model mice, $2 \mathrm{mg} / \mathrm{kg}$ NaHS significantly reduced infarct volume $(26.0 \% \pm 4.4 \%)$ and neurological deficits $(3.7 \pm 0.4) \quad$ (Fig. 1). 1, 4, $8 \mathrm{mg} / \mathrm{kg}$ NaHS also showed the effect of reducing infarct volume, which were $34.6 \% \pm 2.2 \%$, $31.2 \% \pm 3.6 \%$ and $33.4 \% \pm 3.0 \%$, respectively (Fig. 1B). Obviously, $2 \mathrm{mg} / \mathrm{kg}$ of NaHS showed the best effect, which was used in following experiments.

\section{Dose-dependent interruption effect of rapamycin on $\mathrm{H}_{2} \mathrm{~S}$ protection}


As showed in Fig. 2, compared with model group, NaHS treatment alleviated the infarct volume from $44.8 \% \pm 4.2 \%$ to $21.2 \% \pm 2.4 \%$. Subsequently, pretreatment with an autophagy inducer rapamycin, dose-dependently attenuated the protective effects of NaHS on infarct volume, which increased from $21.2 \% \pm 2.4 \%$ to $32.6 \% \pm 3.8 \%$ and $45.4 \% \pm 3.0 \%$, respectively (Fig. 2B). 3-MA, an autophagy inhibitor, also decreased the infarction volume to $17.8 \% \pm 2.0 \%$, presenting a similar effect to $\mathrm{H}_{2} \mathrm{~S}$. These results indicated that $\mathrm{H}_{2} \mathrm{~S}$ may act as an autophagy inhibitor contributing to the reduction of infarction.

\section{Influence of $\mathrm{H}_{2} \mathrm{~S}$ on expression of autophagy-related proteins in cortex and striatum}

To further explore the mechanisms of $\mathrm{H}_{2} \mathrm{~S}$ in autophagy, we examined the expression of LC3-II (Kimura et al. 2009) and p62, the specific biomarkers on autophagic vacuole, in ischemia cortex and striatum by western blot assay. In ischemia cortex the expression of LC3-II was significant up-regulated in model group, whereas $\mathrm{H}_{2} \mathrm{~S}$ suppressed the elevation of LC3-II (Fig. 3A, 3B). p62 was significant down-regulated in model group and was reversed with $\mathrm{H}_{2} \mathrm{~S}$ treatment (Fig. 3A, 3C). Different from the results in cortex, no evident change in NaHS pretreatment was observed in striatum (Fig. 3D-3F). Thereby, we assume that the effect of $\mathrm{H}_{2} \mathrm{~S}$ in autophagy vary from one brain region to another.

On the basis that Beclin-1 complex is vital for initiation of autophagy, we detected the expression level of Beclin-1 in ischemia cortex with western blot. The protein levels of Beclin-1 were significantly increased at $24 \mathrm{~h}$ after ischemia. Unexpectedly, NaHS treatment did not result in significant effect on ischemia-induced up-regulation of Beclin-1 expression (Fig. 4). Collectively, these data demonstrate that the neuroprotective effect of $\mathrm{H}_{2} \mathrm{~S}$ is closely related to its inhibition of autophagy in $\mathrm{I} / \mathrm{R}$ cortex.

\section{DISCUSSION}

This study showed that NaHS, a donor of $\mathrm{H}_{2} \mathrm{~S}$, alleviated the ischemia cerebral injury through decreasing infarct volume and reducing neurobehavioral defect score in MCAO 
mice (Fig. 1). These results were in accordance with the previous research (Yin et al. 2013). Most importantly, we provided the first evidence that the neuroprotection of $\mathrm{H}_{2} \mathrm{~S}$ was associated with autophagy.

We observed that the protective effect of $\mathrm{H}_{2} \mathrm{~S}$ could be suppressed by an autophagy activator, and an autophagy inhibitor, 3-MA exhibited protective effect similar to $\mathrm{H}_{2} \mathrm{~S}$ in this study (Fig. 2B). These data first demonstrated that $\mathrm{H}_{2} \mathrm{~S}$ played a cerebral protective role through autophagy regulation. 3-MA, a PtdIns3K inhibitor, blocks the formation of autophagosomes from upstream signal pathway at the early stage by inhibiting the class III PtdIns3K (Klionsky et al. 2008). Therefore we'd like to know whether $\mathrm{H}_{2} \mathrm{~S}$ influences the formation of autophagosomes. LC3-II and p62, two specific biomarkers on autophagic vacuole were determined with western blot. The result showed that $\mathrm{H}_{2} \mathrm{~S}$ reversed the elevation of LC3-II and the reduction of p62 induced by ischemia (Fig. $3 \mathrm{~A}-3 \mathrm{C}$ ), indicating that the $\mathrm{H}_{2} \mathrm{~S}$ treatment decreased autophagosomes.

However, because decreased autophagosome does not equate with decreased autophagy, the influence of $\mathrm{H}_{2} \mathrm{~S}$ on the elevation of LC3-II and the reduction of p62 may be caused either by the reduction of autophagosome synthesis or by the acceleration of autophagosome degradation (Klionsky et al. 2008). Our results showed that $\mathrm{H}_{2} \mathrm{~S}$ did not influence the expression of Beclin-1 (Fig. 4). As the activity of Beclin-1-VPS34-AMBRA1 complex may not be precisely reflected by Beclin-1 levels (Liu et al. 2016), more definitive studies would be required to determine the role of Beclin-1 complex in the regulation of autophagy pathways for $\mathrm{H}_{2} \mathrm{~S}$. Whether $\mathrm{H}_{2} \mathrm{~S}$ regulates the activity of other autophagy-related complexes, such as ULK1 complex, or even the fusion of autophagosomes with lysosomes has been under investigation in our lab.

In this study we found that $\mathrm{H}_{2} \mathrm{~S}$ manifested different effects on autophagy in cortex and in striatum. It has been reported that hippocampus and cerebral cortex showed different autophagy response to ischemia insults and the diversity of results may be caused by different basal autophagy levels (Diego et al. 2015). Therefore, we suggested that the diverse effect of $\mathrm{H}_{2} \mathrm{~S}$ may be partly dependent on the different levels of basal autophagy 
in cortex and striatum. Additionally, the previous study has demonstrated that endogenous $\mathrm{H}_{2} \mathrm{~S}$, produced in ischemia brain, is mainly distributed in cortex and hippocampus instead of in the striatum (Zhang et al. 2013), which may also contributed to the diversity of intracerebral effect of $\mathrm{H}_{2} \mathrm{~S}$.

In conclusion, this study demonstrates that $\mathrm{H}_{2} \mathrm{~S}$ presents the protective effect on cerebral ischemia in mice, and this effect is associated with decreasing autophagosomes accumulation in ischemia cortex.

\section{DECLARATION OF INTERESTS}

The authors report no conflicts of interest.

\section{ACKNOWLEDGEMENTS}

The present study was supported by the grant from the National Natural Science Foundation of China $(81302763,61071002,81503060)$. We are grateful to Danielle $\mathrm{Hu}$ for careful proof reading.

\section{REFERENCES}

Diego, P.R., Berta, A.S., Irene, L.L., Carlos, C.P., and Arsenio, F.L. 2015. Hippocampus and cerebral cortex present a different autophagic response after oxygen and glucose deprivation in an ex vivo rat brain slice model. Neuropathol. Appl. Neurobiol. 41(4): e68-79. PMID:24861158

Finan, J.D., Cho, F.S., Kernie, S.G., and Morrison, B. 2016. Intracerebroventricular administration of chondroitinase $\mathrm{ABC}$ reduces acute edema after traumatic brain injury in mice. BMC Res. Notes, 9(1): 160. PMID:26969621

Gao, L., Jiang, T., Guo, J., Liu, Y., Cui, G., Gu, L., et al. 2012. Inhibition of autophagy contributes to ischemic postconditioning-induced neuroprotection against focal cerebral ischemia in rats. PLoS ONE, 7(9): e46092. PMID:23029398

Hara, H., Huang, P.L., Panahian, N., Fishman M.C., and Moskowitz, M.A. 1966. Reduced brain edema and infarction volume in mice lacking the neuronal isoform of nitric oxide synthase after transient MCA occlusion. J. Cereb. Blood Flow Metab. 16(4): 605-611. PMID:8964799

Jackman, K., Kunz, A., and Iadecola, C. 2011. Modeling focal cerebral ischemia in vivo. 
Methods Mol. Biol. 793: 195-209. PMID:21913102

Jang, H., Oh, M.Y., and Kim, Y.J. 2014. Hydrogen sulfide treatment induces angiogenesis after cerebral ischemia. J. Neurosci. Res. 92(11): 1520-1528. PMID:24939171

Jiang, H., Xiao, J., Kang, B., Zhu, X., Xin, N., and Wang, Z. 2015. PI3K/SGK1/GSK3 $\beta$ signaling pathway is involved in inhibition of autophagy in neonatal rat cardiomyocytes exposed to hypoxia/reoxygenation by hydrogen sulfide. Exp. Cell Res. pii: S0014-4827(15)30035-5. PMID:26163895

Kimura, S., Fujita, N., Noda, T., and Yoshimori, T. 2009. Monitoring autophagy in mammalian cultured cells through the dynamics of LC3. Methods Enzymol. 452: 1-12. PMID:19200872

Klionsky, D.J., Abeliovich, H., Agostinis, P., Agrawal, D.K., Aliev, G., Askew, D.S., et al. 2008. Guidelines for the use and interpretation of assays for monitoring autophagy in higher eukaryotes. Autophagy, 4(2): 151-175. PMID:18188003

Li, L., Jiang, H.K., Li, Y.P., and Guo, Y.P. 2015. Hydrogen sulfide protects spinal cord and induces autophagy via miR-30c in a rat model of spinal cord ischemia-reperfusion injury. J. Biomed. Sci. 22(1): 50. PMID:26149869

Liu, C.C., Lin, Y.C., Chen, Y.H., Chen, C.M., Pang, L.Y., Chen, H.A., et al. 2016. Cul3-KLHL20 Ubiquitin Ligase Governs the Turnover of ULK1 and VPS34 Complexes to Control Autophagy Termination. Mol. Cell, 61(1): 84-97. PMID:26687681

Nazio, F., Strappazzon, F., Antonioli, M., Bielli, P., Cianfanelli, V., Bordi, M., et al. 2013. mTOR inhibits autophagy by controlling ULK1 ubiquitylation, self-association and function through AMBRA1 and TRAF6. Nat. Cell Biol. 15(4): 406-416. PMID:23524951

Pradip, K.K., Anuradha, K., and Neetu, T. 2015. Role of hydrogen sulfide in brain synaptic remodeling. Methods Enzymol. 555: 207-229. PMID:25747482

Szabó, C. 2007. Hydrogen sulfide and its therapeutic potential. Nat. Rev. Drug Discov. 6(11): 917-935. PMID:17948022

Thal, S.E., Thal, S.C., and Plesnila, N. 2010. Characterization of a 3-vessel occlusion model for the induction of complete global cerebral ischemia in mice. J. Neurosci. Methods, 192(2): 219-227. PMID:20688105

Wong, P.M., Puente, C., Ganley, I.G., and Jang, X. 2013. The ULK1 complex: sensing nutrient signals for autophagy activation. Autophagy, 9(2): 124-137. PMID:23295650

Yamamoto, A., Yue Z. 2014. Autophagy and its normal and pathogenic states in the brain. Annu. Rev. Neurosci. 37: 55-78. PMID:24821313

Yin, J., Tu, C., Zhao, J., Ou, D., Chen, G., Liu, Y., et al. 2013. Exogenous hydrogen sulfide protects against global cerebral ischemia/reperfusion injury via its anti-oxidative, anti-inflammatory and anti-apoptotic effects in rats. Brain Res. 1491: 188-196. PMID:23123706 
Zhang, M., Shan H., Chang, P., Wang, T., Dong, W., Chen, X. et al. 2014. Hydrogen sulfide offers neuroprotection on traumatic brain injury in parallel with reduced apoptosis and autophagy in mice. PLoS ONE, 9(1): e87241. PMID:24466346

Zhang, X., and Bian, J.S. 2014. Hydrogen sulfide: a neuromodulator and neuroprotectant in the central nervous system. ACS Chem. Neurosci. 5(10): 876-883. PMID:25230373

Zhang, Y., Tang, Z.H., Ren, Z., Qu, S.L., Liu, M.H., Liu, L.S., et al. 2013. Hydrogen sulfide, the next potent preventive and therapeutic agent in aging and age-associated diseases. Mol. Cell. Biol. 33(6): 1104-1113. PMID:23297346

Zhao, W., Zhang, J., Lu, Y., and Wang, R. 2001. The vasorelaxant effect of H2S as a novel endogenous gaseous K (ATP) channel opener. EMBO J. 20(21): 6008-6016. PMID: 11689441

\section{Figure Legends}

Fig. 1.

Neuroprotective Effect of $\mathrm{H}_{2} \mathrm{~S}$ in Mice. Mice were treated with different dose of NaHS at onset of MCAO, and were killed 24 hours after ischemia. (A) Representatives of TTC stained brain slices. (B) Quantitative analysis of cerebral infarct volume. (C) Statistical results of neurological deficits 22 hours after ischemia. Bar represents mean $\pm \mathrm{SEM}$.

Fig. 2.

Dose-dependent interruption effect of rapamycin on $\mathrm{H}_{2} \mathrm{~S}$ protection. Mice were intraventricular injected with different dose of rapamycin 10 minutes before ischemia in presence of NaHS or injected with 3-MA alone. (A) Representative TTC staining of brain sections. (B) Statistical analysis of brain infarct volume. Bar represents mean $\pm \mathrm{SEM}$.

Fig. 3.

Effect of $\mathrm{H}_{2} \mathrm{~S}$ on expression of autophagy-related proteins in cerebral Ischemia cortex and striatum. Tissues were isolated 24 hours after ischemia. (A) Representatives western blots of LC3-II and p62 in cortex. (B-C) Protein expression of LC3-II and p62 in ischemia cortex. (D) Representatives western blots of LC3-II and p62 in striatum. (E-F) Protein expression of LC3-II and p62 in ischemia striatum. Levels of $\beta$-actin protein were used as the control. Quantitative analysis was performed with Imagelab Software. Bar represents mean $\pm \mathrm{SEM}$.

Fig. 4. 
Effect of $\mathrm{H}_{2} \mathrm{~S}$ on Beclin-1 complex. (A) Representatives western blots of Beclin-1 in ischemia cortex. (B) Quantitative Analysis of Beclin-1 expression level. Bar represents mean \pm SEM. 
(A)

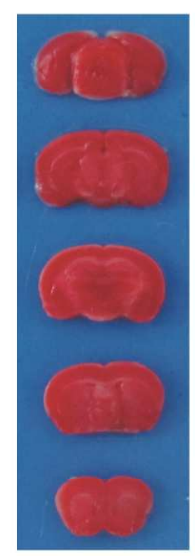

Sham

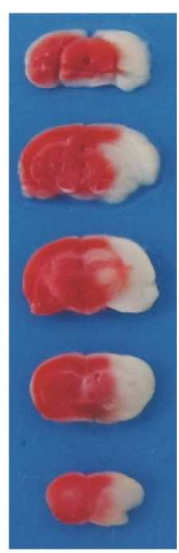

Model

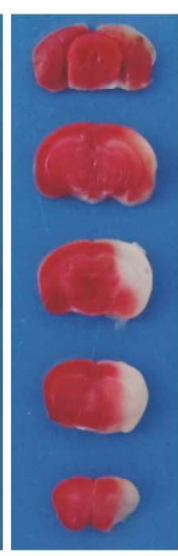

1

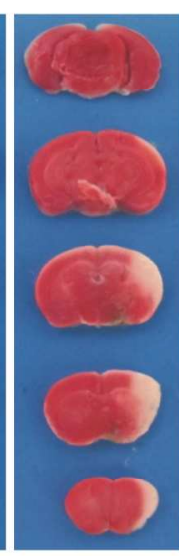

2

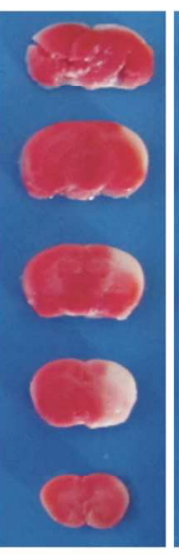

4

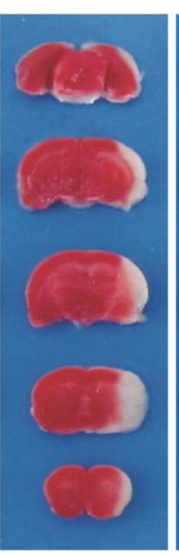

8

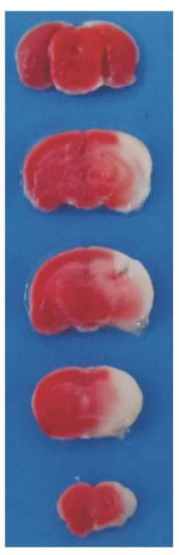

16

(B)

$\mathrm{NaHS}(\mathrm{mg} / \mathrm{kg})$

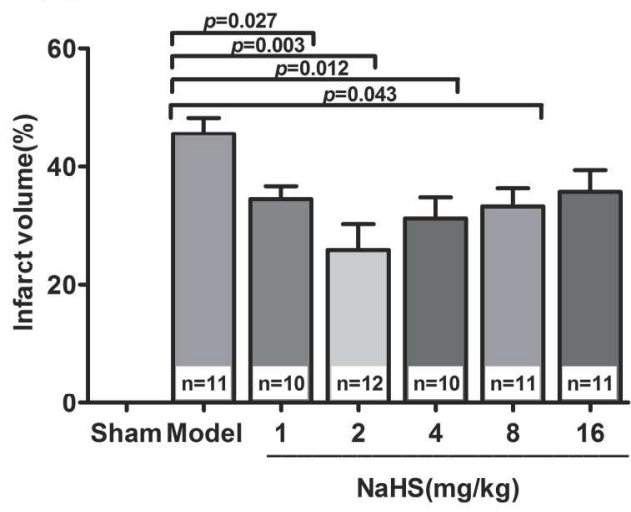

(C)

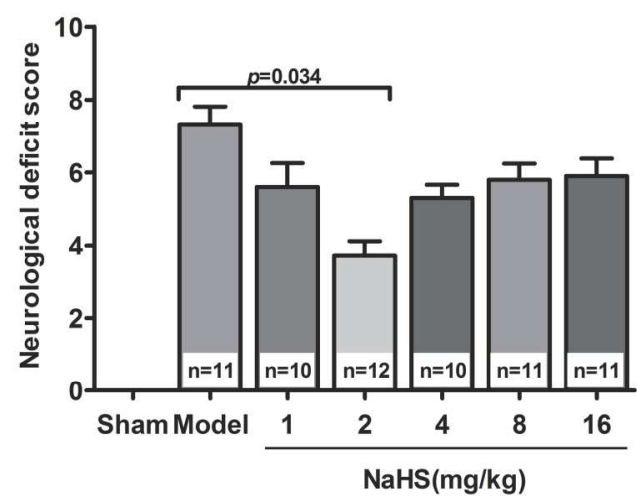

Fig. 1.

Neuroprotective Effect of $\mathrm{H} 2 \mathrm{~S}$ in Mice. Mice were treated with different dose of NaHS at onset of MCAO, and were killed 24 hours after ischemia. (A) Representatives of TTC stained brain slices. (B) Quantitative analysis of cerebral infarct volume. (C) Statistical results of neurological deficits 22 hours after ischemia. Bar represents mean \pm SEM. 

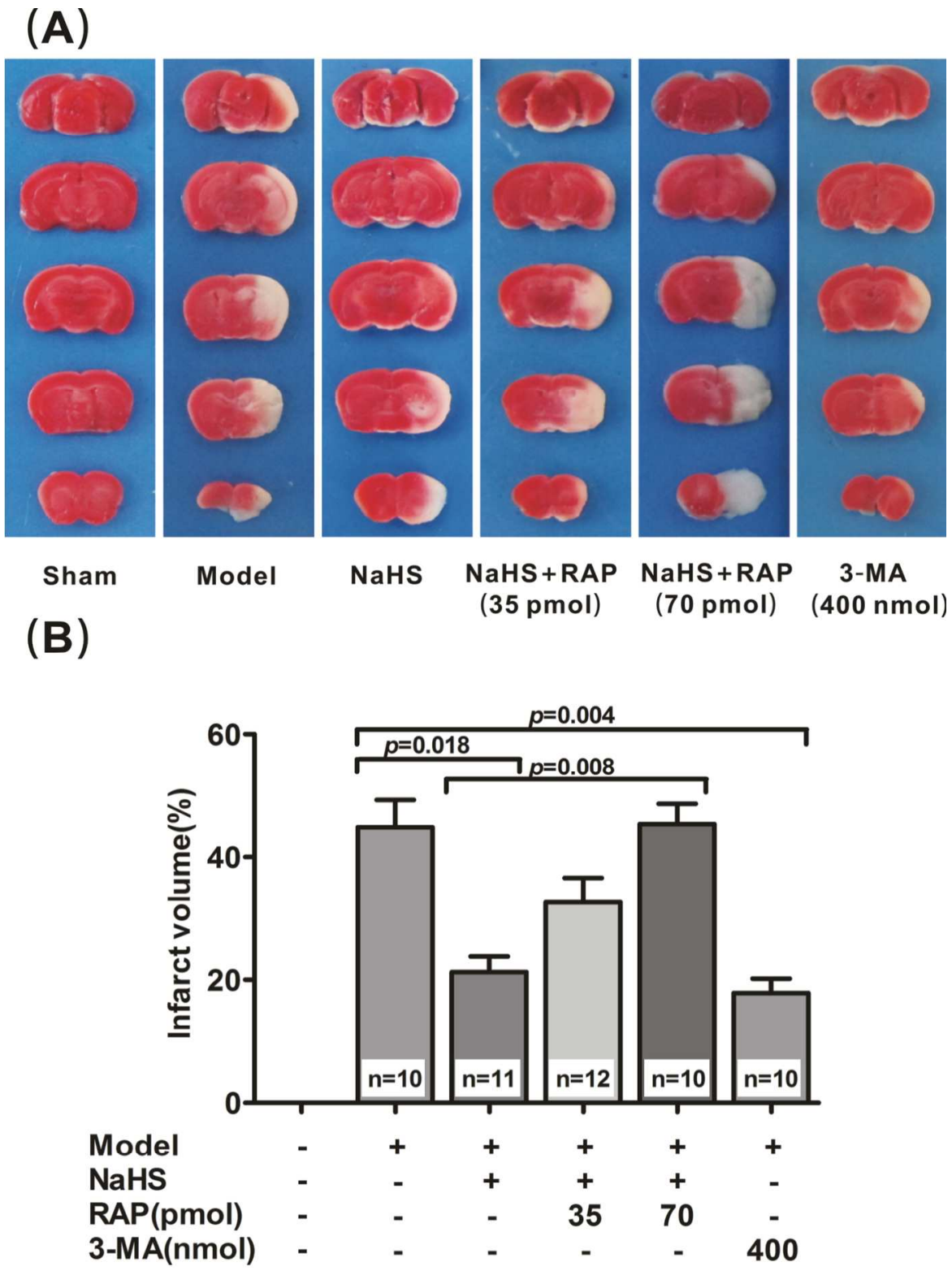

Fig. 2.

Dose-dependent interruption effect of rapamycin on H2S protection. Mice were intraventricular injected with different dose of rapamycin 10 minutes before ischemia in presence of NaHS or injected with 3-MA alone. (A) Representative TTC staining of brain sections. (B) Statistical analysis of brain infarct volume. Bar represents mean \pm SEM. 
(A)

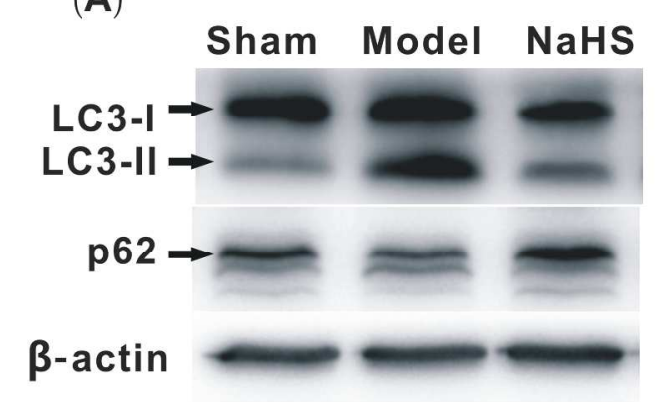

(B)
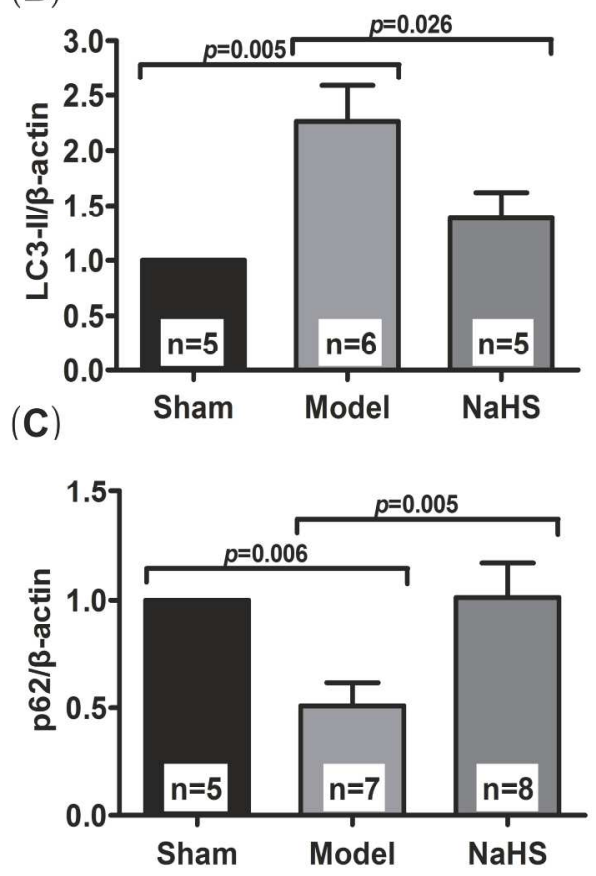

(D)

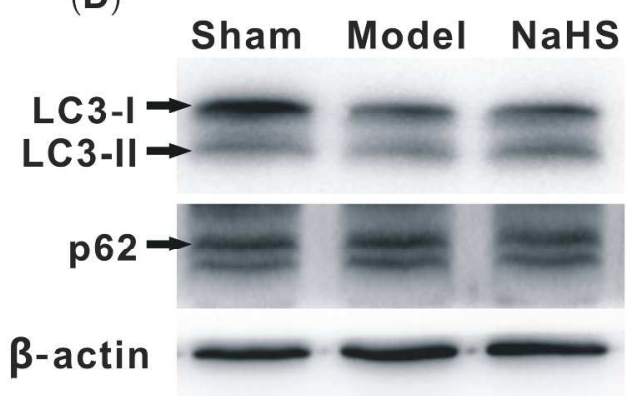

(E)
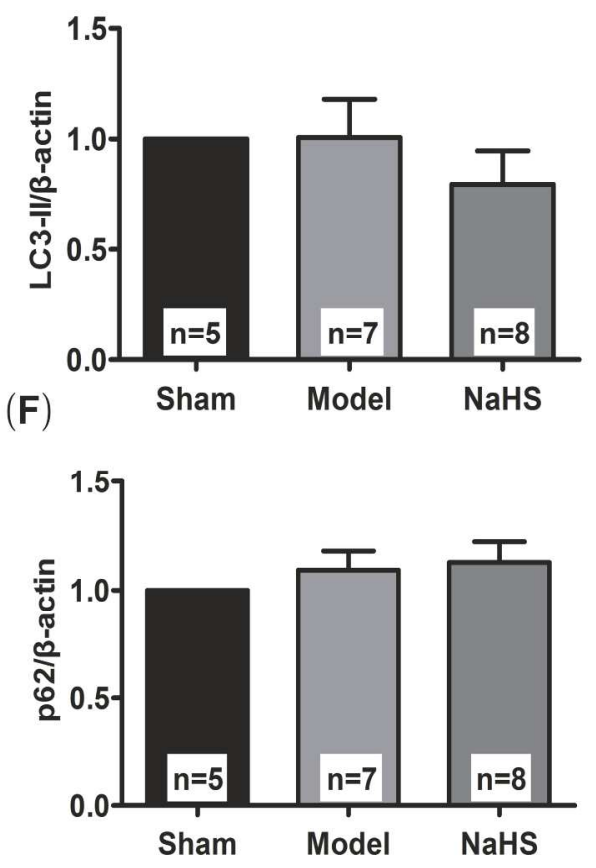

Fig. 3.

Effect of $\mathrm{H} 2 \mathrm{~S}$ on expression of autophagy-related proteins in cerebral Ischemia cortex and striatum. Tissues were isolated 24 hours after ischemia. (A) Representatives western blots of LC3-II and p62 in cortex. (B-C) Protein expression of LC3-II and p62 in ischemia cortex. (D) Representatives western blots of LC3-II and p62 in striatum. (E-F) Protein expression of LC3-II and p62 in ischemia striatum. Levels of $\beta$-actin protein were used as the control. Quantitative analysis was performed with Imagelab Software. Bar represents mean \pm SEM. 
(A)

\section{Sham Model NaHS}

\section{Beclin-1}

\section{$\beta$-actin}

(B)

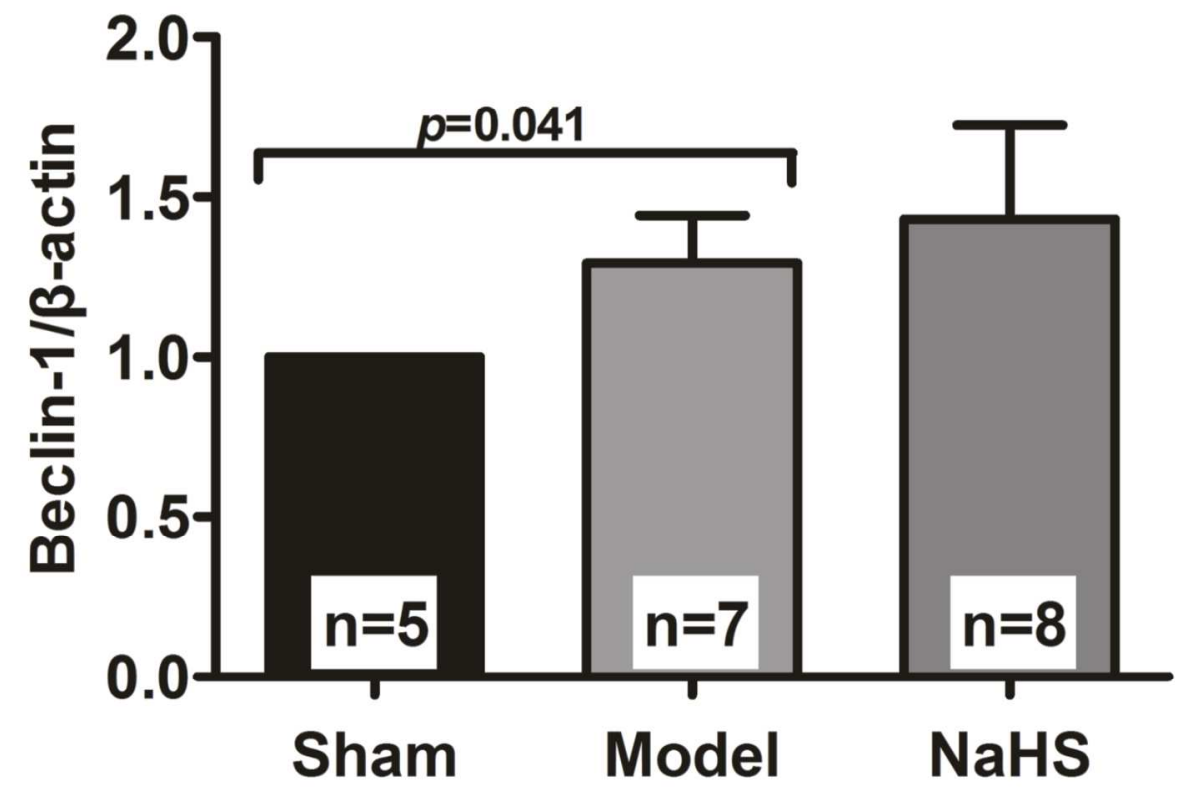

Fig. 4.

Effect of H2S on Beclin-1 complex. (A) Representatives western blots of Beclin-1 in ischemia cortex. (B) Quantitative Analysis of Beclin-1 expression level. Bar represents mean \pm SEM. 